\title{
Identification of possible dynamical drivers for long-term changes in temperature and rainfall patterns over Europe
}

\author{
Peter Hoffmann $^{1}$ (D) . Arne Spekat ${ }^{1}$ \\ Received: 25 February 2020 / Accepted: 3 September 2020 / Published online: 13 October 2020 \\ (C) The Author(s) 2020
}

\begin{abstract}
This study looks into the question to what extent long-term change patterns of observed temperature and rainfall over Europe can be attributed to dynamical causes, in other words: Are the observed changes due to a change in frequency of the patterns or have the patterns' dynamical properties changed? By using a combination of daily meteorological data and a European weather-type classification, the long-term monthly mean temperature and precipitation were calculated for each weathertype. Subsequently, the observed weather-type sequences were used to construct analogue time series for temperature and precipitation which only include the dynamical component of the long-term variability since 1961 . The results show that only a fraction of about $20 \%$ of the past temperature rise since 1990 , which for example amounted to $1{ }^{\circ} \mathrm{C}$ at the Potsdam Climate Station can be explained by dynamical changes, i.e. most of the weather-types have become warmer. Concerning long-term changes of seasonal rainfall patterns, a fraction of more than $60 \%$ is considerably higher. Moreover, the results indicate that for rainfall compared with temperature, the decadal variability and trends of the dynamical component follow the observed ones much stronger. Consequently, most of the explained seasonal rainfall variances can be linked to changes in weather-type sequences in Potsdam and over Europe. The dynamical contribution to long-term changes in annual and seasonal rainfall patterns dominates due to the fact that the alternation of wet and dry weather-types (e.g. the types Trough or High pressure over Central Europe), their frequencies and duration has significantly changed in the last decades.
\end{abstract}

\section{Introduction}

The main trigger for average weather as well as extreme events like rainfall of high intensity or duration, heat waves and severe storms is specific synoptic patterns (e.g. Donat et al. 2009; Stucki et al. 2012; Hoy et al. 2013; Kornhuber et al. 2019). The sea level pressure (surface), the geopotential height at $500 \mathrm{hPa}$ (middle troposphere) and the meridional wind velocity at $300 \mathrm{hPa}$ (upper troposphere) are

Electronic supplementary material The online version of this article (https://doi.org/10.1007/s00704-020-03373-3) contains supplementary material, which is available to authorized users.

Peter Hoffmann

peterh@pik-potsdam.de

1 Potsdam Institute for Climate Impacts Research, Research Domain: Climate Resilience, Telegrafenberg A31, 14412 Potsdam, Germany essential meteorological variables for the characterization and categorization of the synoptical situation over a region such as the North-Atlantic and Europe (e.g. Hess and Brezowsky 1977; James 2007; Huth et al. 2008). Reported changes in occurrence frequencies and durations of weather patterns (e.g. Kyselý 2008; Werner et al. 2008; Cahynová and Huth 2009; Hoy et al. 2012; Kučerová et al. 2016; Hoffmann 2017; Murawski et al. 2018) as well as their sequences are already evident and can be likely linked to the ongoing climate changes due to the differential warming rates between land and ocean on the one hand and high and low latitudes on the other hand (e.g. Coumou et al. 2014; Coumou et al. 2015; Molnos et al. 2017; Coumou et al. 2018). However, the development of mostly objective criteria for the extraction of relevant synoptical features from reanalyses or climate simulations is difficult and still controversially discussed (e.g. Tveito and Huth 2016; Kučerová et al. 2016). Due to the considerable bias of climate simulations, a synoptic assessment of simulated weather and extreme weather episodes provides an added 
value for plausibility checks, analogous to the interpretation of the blocking frequency (e.g. Davini and D'Andrea 2016; Woollings et al. 2018; Schaller et al. 2018). Extreme weather events will become more severe if the persistence of certain weather patterns only slightly increases (e.g. Pfleiderer et al. 2019). Recent heat extremes over Europe in summer 2003, 2018 and 2019 (e.g. Wolf et al. 2018) as well as events characterized by continuous rainfall in 2002, 2013 and 2017 over Central Europe can be partly attributed to the persistence of specific synoptic patterns and dynamical causes (e.g. Casanueva et al. 2014).

However, another relevant factor for the globally increasing numbers of extreme weather events are longterm changes in the characteristic and intensity of weather patterns that establish new temperature and precipitation records (e.g. Coumou et al. 2013; Lehmann et al. 2015s). With rising global temperatures (WMO 2019), more water evaporates over the ocean areas. This energetic reason is partly apparent in the intensity shift of hydro-climatic extreme events (Trenberth 2011; Hattermann et al. 2018). One of the most frequently asked questions concerns the attribution of current extreme events or episodes to the ongoing (anthropogenic) climate change. Although this answer can currently only be given by climate model simulations (e.g. Trenberth et al. 2015; Vautard et al. 2016; Pfahl et al. 2017; Pasini et al. 2017), it would be a great step forward to assign the observed climate change signals according to their main causes, i.e. thermodynamics and dynamics.

Long-term change analyses of total precipitation patterns over Europe (e.g. Schönwiese et al. 2003; van den Besselaar et al. 2012; Hoy et al. 2013) show mostly increasing trends over Northern Europe (NE) and decreasing trends over Southern Europe (SE) as well as mostly increasing trends in winter over most parts of Central Europe (e.g. Werner et al. 2008). A possible attribution of the observed sub-seasonal change patterns to atmospheric processes and teleconnection patterns were studied by (e.g. Casanueva et al. 2014; Fleig et al. 2015; Ummenhofer et al. 2017s). Clearly changes in precipitation and temperature are caused by both, the changes in the occurrence frequency of synoptic patterns and local hydrothermal properties, respectively. The ratio of the two influencing factors on the total share is still unclear.

This paper aims to answer the question: How large is the dynamical share of the observed change in seasonal temperature and precipitation patterns over Europe? In the following sections, we describe the datasets used including initial analyses (Section 2) and the methodology how to decouple the dynamical component from the total long-term change and variability (Section 3 ). The results are distinguished between local (Potsdam) and regional
(Europe) as well as annual (Section 4) and seasonal components (Supplementary Material). Finally, we close with a conclusion of our findings (Section 5).

\section{Data and initial analyses}

The data used here are meteorological observations or quantities derived from them, exclusively. These are available publicly, long-term and in near real-time. No further simulation data was used.

\subsection{Potsdam climate data for over 100 years}

The meteorological station Potsdam (WMO-ID: $10379^{1}$ ) is unique because it changed neither location nor measurement program since 1 January 1893 , i.e. more than 100 years. The so-called Secular Station atop the Telegrafenberg hill $(81 \mathrm{~m})$ in the south-west of Potsdam $\left(52^{\circ} 23^{\prime} \mathrm{N}, 13^{\circ} 04^{\prime} \mathrm{E}\right)$ is still operated by the German Meteorological Service (DWD) and is tightly linked to scientific works and services at the Potsdam Institute for Climate Impacts Research (PIK): https:// www.pik-potsdam.de/services/climate-weather-potsdam.

Initial analysis An example using the long-term Potsdam station data in an operational way is given in Fig. 1. It brings the year 2018 (black line) in perspective with past years (red lines) using annually cumulative trajectories of temperature (green band) and rainfall (blue band). For reasons of comparability, the precipitation values have been scaled by a factor of 3 . The warmest year so far was in $2014\left(10.91{ }^{\circ} \mathrm{C}\right)$ which was surpassed in $2018\left(11.23^{\circ} \mathrm{C}\right)$ by a wide margin. We developed an interactive tool, using mpld3 python libraries, which permits an explorative data analysis by highlighting trajectories for individual years and selected indicators (mouse over). It is evident that the cumulative condition in 2018 was unusual since it was well above (temperature) and below (rainfall) conditions in other years. Moreover, large parts of central and northern Europe were subject to an extreme rain deficit in 2018 (WMO 2019). Although the graph just shows the conditions after 1961, it should be added that the Potsdam station data established the year 2018 not only as the warmest but also one of the driest year on record. In the course of this article, the dynamical part of the annual and seasonal temperature and precipitation change at that location will be estimated by combining it with a time series of European weather-types.

\footnotetext{
${ }^{1}$ http://www.wetterdiagramme.de/wetterstationen/10379_Potsdam Bericht_2016.pdf
} 
Fig. 1 Annually cumulative daily mean temperature (green band) and daily rainfall (blue band) trajectories at Potsdam from 1961 to 2017. The red trajectories represent individual years. The year 2018 is plotted as black line

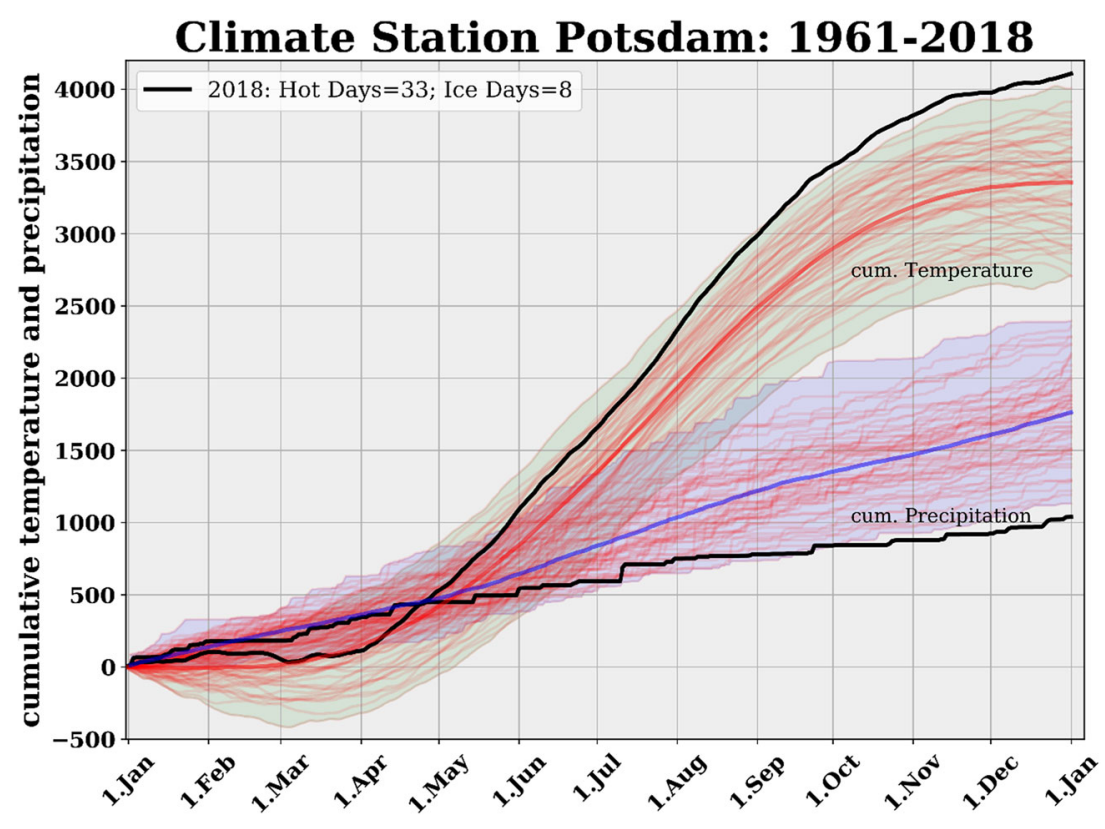

\subsection{European gridded observation dataset}

The Potsdam station data enable a distinct local assessment of climate developments, but how about the changing conditions in other parts of Europe? The most commonly used meteorological observation dataset to study long-term changes in daily mean temperature (tg) and daily rain rate (rr) over Europe is European gridded observation dataset (E-OBS) (van den Besselaar et al. 2011) with the current version V20.0 (1950-2018). Station measurements at 11422 sites across Europa were homogenized and are provided on a $0.25^{\circ}$ grid covering the European land mass. EOBS data are used in this study (1) to identify long-term climate change signals of the surface quantity temperature and rainfall and (2) to assign long-term monthly averaged values per weather-type and grid cell. In combination with a weather-type classification, the dynamical component of the long-term change signal will be estimated and quantified.

\subsection{Hess/Brezowsky weather-types}

In order to link atmospheric states to regional or local conditions, it is common to employ a classification methodology which identifies distinct configurations of atmospheric features. This is the so-called circulationto-environment strategy, defined in Yarnal (1993). One of the longest available classifications of weather-types over Europe is based on the methodology by Hess and Brezowsky (1977). It distinguishes between 30 different categories of circulation shapes and synoptical patterns. The HB classification is constantly applied and the results are available on a near-real time basis through the
German Meteorological Service (DWD) ${ }^{2}$. By definition, the minimum duration of one HB weather-type is 3 days.

The concept to identify synoptical patterns over Europe builds upon (1) synoptic experience and (2) two quantities: the $500 \mathrm{hPa}$ geopotential height field and the mean sea level pressure field over the European-North-Atlantic sector. Based on long-term reanalyses, James (2007) has made an attempt to reproduce the HB classification by objective, algorithmic means. He achieved a hit-rate lower than $50 \%$ (see Tab.3 in James 2007) depending on the pattern. There are numerous other atmospheric circulation pattern classification schemes. They are summarized in Huth et al. (2008). However, which classification scheme is the most suitable one is not the subject of the study. There was a COST Action (733, on Harmonisation and Applications of Weather Types Classifications for European Regions) in which methods were comprehensively evaluated. Please refer to Tveito and Huth (2016). It should be noted that the weather-types according to Hess and Brezowsky (1977) fulfill 4 main criteria. They are (1) long-term, (2) synoptically meaningful, (3) valid for all of Europe and (4) available in near-real time.

Initial analysis A combined local analysis using daily maximum temperature, daily rainfall at Potsdam (columns) and daily European HB weather-types (denoted by their abbreviations) is given in the histograms shown in Fig. 2 . Each column represents a value range (bin). The height of the columns is determined by the number of contributing weather-types per temperature bin (width: $1 \mathrm{~K}$ ) or rainfall

\footnotetext{
${ }^{2}$ https://www.dwd.de/DE/leistungen/grosswetterlage/
} 


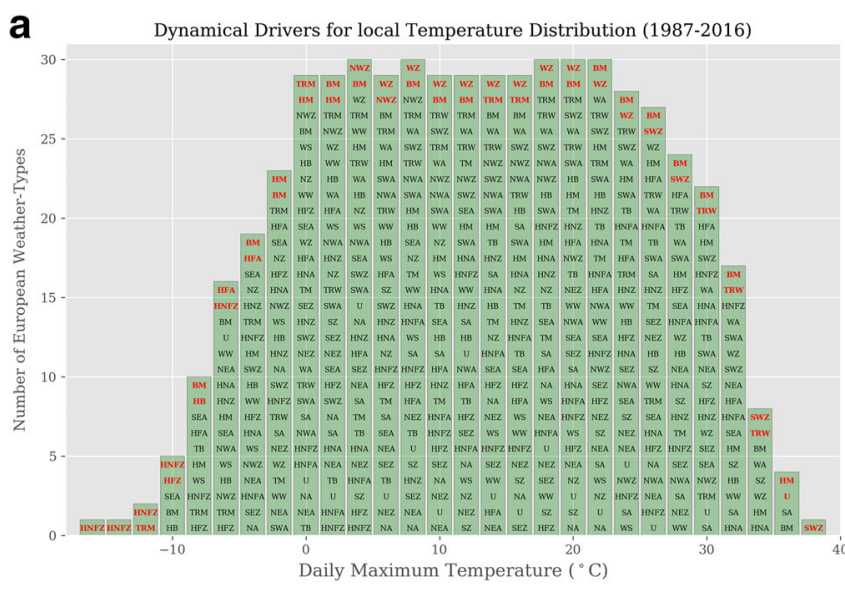

Fig. 2 Histogram of the daily maximum temperature a and the daily rainfall $\mathbf{b}$ at Potsdam assigned according to the contributing European $\mathrm{HB}$ weather-types. Hot days $\left(T_{\max }>30^{\circ} \mathrm{C}\right)$ are mainly caused by $\mathrm{HB}$

bin (width: $5 \mathrm{~mm} /$ day); if the column extends to 30 units, this means that every HB weather-type contributes to that temperature or precipitation range. Within each column, the contributing patterns are ordered by frequency with the most frequent occurrences highlighted in red. Since the focus is on extremes, the rightmost columns (maximum temperature above $30^{\circ} \mathrm{C}$ or precipitation above $20 \mathrm{~mm} /$ day) are of relevance. It turns out that high-temperature extremes (Fig. 2a) are mainly caused by HB weather-types High over Central Europe (HM), Zonal Ridge across Central Europe (BM) and South-West Cylonic (SWZ). Wet extremes (Fig. 2b) are most frequently occurring in conjunction with HB weather-types Trough over Central Europe (TRM) and Low pressure over Central Europe (TM). Under current climate conditions, these HB weather-types are dominating the summer-half year, as shown in Hoffmann (2017). It should be kept in mind that the analyses which are summarized in Fig. 2 identify candidates of European HB weather-types in conjunction with local extremes at the Potsdam station. In other regions, such as the Mediterranean area, other combinations and relationships can be found.

\section{Methods}

The methodology to identify the dynamical contribution on the long-term observed changes of temperature and rainfall patterns is based on a combination of daily observed meteorological variables for Europe, extracted from the E-OBS dataset (van den Besselaar et al. 2011) and an operationally provided classification of $30 \mathrm{HB}$ weathertypes over Europe (Hess and Brezowsky 1977). Therefore, each point in Europe is characterized by these features: (i) the daily mean temperature and rainfall on the local

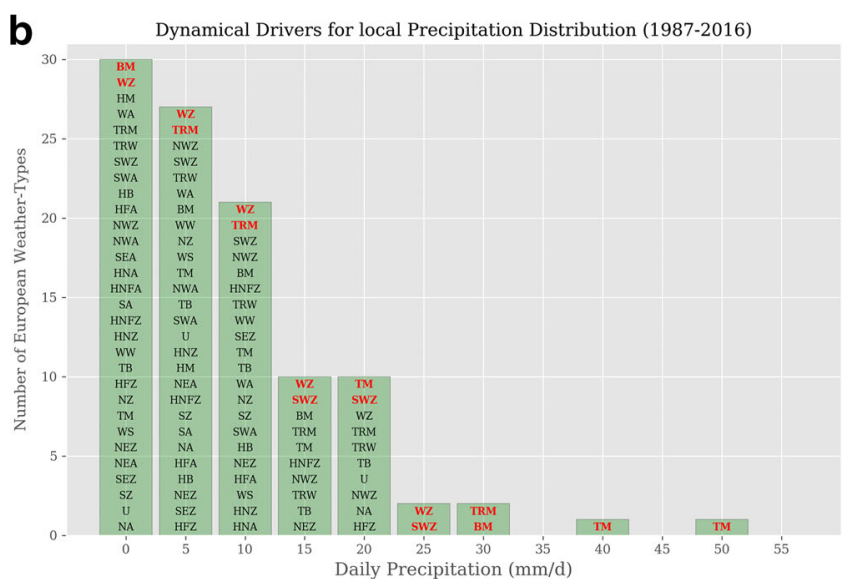

weather-types: SWZ, BM, HM. Very wet days $(P r>30 \mathrm{~mm} / d)$ are mainly caused by HB weather-types: TRM, TM

scale and (ii) the simultaneously occurring HB weather-type category on the continental scale.

\subsection{Weather-type characteristics}

Based on the initial analyses of Potsdam station data, the candidate HB weather-types for extreme temperature and rainfall are known. The follow-up question is: How would the annual cycle of temperature and precipitation appear, if each day of the year belongs to just one weather type? Which leads to the question: What are the characteristics of certain weather-types over the year, compared to the actual behaviour?

To begin with, both datasets from 1961 to 2018 are used to compute long-term monthly $(\mathrm{m})$ means of temperature $\left(\bar{T}_{m, k}\right)$ and daily precipitation $\left(\bar{R}_{m, k}\right)$ for each HB weathertype $(k)$. In the next step, we generate analogue time series of temperature and precipitation by using the climatological values which are specific for a month and a weather-type, as shown in Table 1. Such a matrix is later shown in Fig. 6b, $\mathrm{d}$ in Section 4. It illustrates the local representation and shaping of each HB weather-type regarding temperature and precipitation for every month (e.g. Nemešová and Klimperová 1995). Furthermore, it allows to identify cold and warm as well as dry and wet weather-types. Finally, the original and generated daily time series are aggregated and compared in terms of long-term changes and possible dynamical factors caused by new dominate HB weathertypes. In order to extend this approach to the continental scale, we combine the daily HB weather-type classification data with a gridded dataset (E-OBS).

Initial analysis One local result of such a comparison of annual cycles for Potsdam is shown in Fig. 3 for 
Table 1 Example of a daily station-related assignment table for Potsdam from 1961 to 2018: date (1-3), European weather-type (4), daily mean temperature (5), daily precipitation (6) and the long-term monthly averaged values per weather-type $(7,8)$

\begin{tabular}{llllllll}
\hline Day & Month & Year & $\begin{array}{l}\text { Weather } \\
\text { type }\end{array}$ & $\begin{array}{l}\text { tot } \\
\text { tg }\end{array}$ & $\begin{array}{l}\text { tot } \\
\text { rr }\end{array}$ & $\begin{array}{l}\text { dyn } \\
\text { tg }\end{array}$ & $\begin{array}{l}\text { dyn } \\
\text { rr }\end{array}$ \\
\hline 1 & 1 & 1961 & WW & 1.00 & 0.00 & 1.2 & 1.6 \\
2 & 1 & 1961 & WW & 0.20 & 2.80 & 1.2 & 1.6 \\
3 & 1 & 1961 & WW & 3.00 & 3.70 & 1.2 & 1.6 \\
4 & 1 & 1961 & WZ & 2.00 & 0.80 & 4.3 & 3.0 \\
5 & 1 & 1961 & WZ & 1.50 & 0.50 & 4.3 & 3.0 \\
6 & 1 & 1961 & WZ & 0.90 & 0.00 & 4.3 & 3.0 \\
7 & 1 & 1961 & WZ & 1.30 & 0.00 & 4.3 & 3.0 \\
8 & 1 & 1961 & WZ & 2.10 & 3.60 & 4.3 & 3.0 \\
9 & 1 & 1961 & WZ & 2.30 & 5.10 & 4.3 & 3.0 \\
10 & 1 & 1961 & WZ & 1.80 & 1.80 & 4.3 & 3.0 \\
$\vdots$ & $\vdots$ & $\vdots$ & $\vdots$ & $\vdots$ & $\vdots$ & $\vdots$ & $\vdots$ \\
21 & 12 & 2018 & NWZ & 7.35 & 6.30 & 2.1 & 3.7 \\
22 & 12 & 2018 & NWZ & 5.33 & 6.10 & 2.1 & 3.7 \\
23 & 12 & 2018 & NWZ & 5.65 & 2.90 & 2.1 & 3.7 \\
24 & 12 & 2018 & NWA & 1.18 & 0.30 & 2.8 & 0.6 \\
25 & 12 & 2018 & NWA & 4.60 & 0.00 & 2.8 & 0.8 \\
26 & 12 & 2018 & NWA & 5.25 & 0.00 & 2.8 & 0.8 \\
27 & 12 & 2018 & NWA & 5.03 & 0.50 & 2.8 & 0.8 \\
28 & 12 & 2018 & NWA & 5.60 & 0.30 & 2.8 & 0.8 \\
29 & 12 & 2018 & NWA & 4.88 & 0.80 & 2.8 & 0.8 \\
30 & 12 & 2018 & NWA & 5.45 & 4.80 & 2.8 & 0.8 \\
31 & 12 & 2018 & NWA & 5.80 & 0.10 & 2.8 & 0.8 \\
\hline
\end{tabular}

temperature (a) and precipitation (b). It is assumed that one year is determined by only one single weather-type. For temperature (Fig. 3a), the lines represent a so-called normal year (grey), a BM-year (red), a TRM-year (blue) and a WZ-year (green). The highest similarity to a normal year is found for a BM-year. Larger differences are only apparent in summer due to large-scale anticyclonic conditions over
Europe often associated with a lot of sunshine and high temperature. The so-called WZ-year is much colder in summer and clearly warmer in winter. The magnitude of the annual cycle is weak compared with others. This weather-pattern is associated with a stronger influence of the North Atlantic on the weather in Central Europe. The lowest temperature in all months is connected to a TRM weather-type. (a)

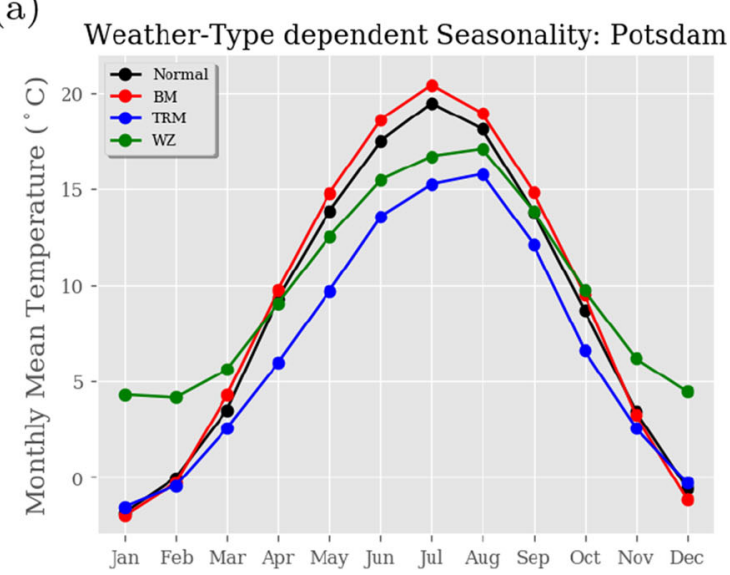

(b)

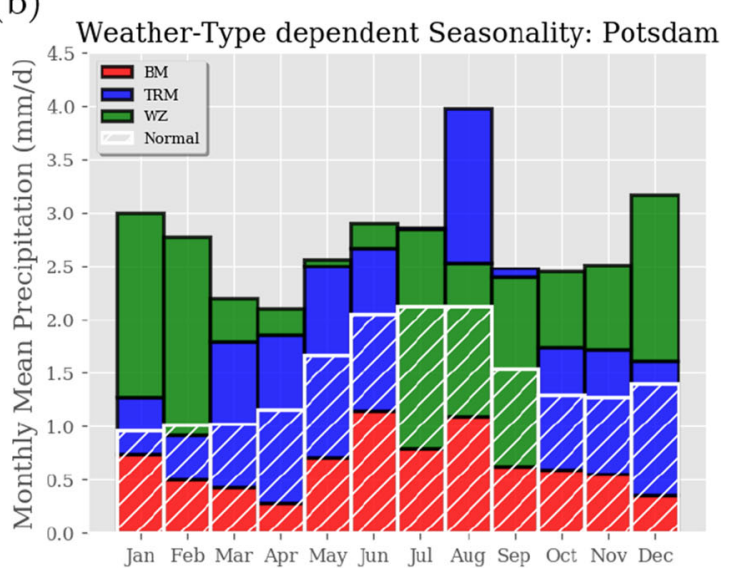

Fig. 3 Long-term 1961-2018 mean annual cycles of monthly mean temperature a and monthly mean rainfall per day b at Potsdam: all weather-types (black or stripped), only BM weather-type (red), only TRM weather-type (blue) and only WZ weather-type (green) 
The mean precipitation conditions are shown by white stippled boxes (Fig. 3b). In a BM-year (red), the monthly amounts would be much below average of the normal year (stippled), whereas years that would be consisting of just TRM (blue) or just WZ (green) would have abovenormal precipitation for each month. The highest monthly precipitation occurs in August and TRM-year. In other words: A so-called BM-year would be characterized by less rainfall over the year, hot summer and cold winter. In spring and autumn, the temperature curve has a maximum compared with the slope of a normal year. The transition period from summer to winter conditions is short. However, such an idealized season (red) is rather close to real conditions (grey). In a so-called WZ-year, the seasonality is less represented by colder summers and warmer winters compared with normal conditions. But the precipitation is higher in all months. The TRM-year exhibits cold winters and summers as well as the largest amount of precipitation in the summer half-year with a maximum in August.

\subsection{Cumulative anomalies}

Although the analyzed time series are seasonally and annually averaged, they are sufficiently long for the identification of emerging trends. Due to the strong interannual variability of the annual values, however, those long-term trends are quite difficult to identify. In order to extract a climate change signal, the cumulative anomalies from 1961 to 2018 compared with the climate reference period 1961-1990 divided by the number of years after 1990 is computed:

$A_{i}=\frac{1}{N-30} \cdot \sum_{i}^{N}\left(a_{i}-\bar{a}\right)$

where $A_{i}$ is the annual time series of cumulative anomalies of $a_{i}-\bar{a}, N$ the total number of years from 1961 to 2018 and $\bar{a}$ the mean value for the climate normal period 1961-1990. This is a non-parametric approach to measure long-term changes and variability. This methodology is similar to the non-parametric Mann-Kendall trend test and the Theil-Sen trend line estimation (Gilbert 1987). Due to the accumulation of anomalies, we clearly see an upward or downward trend. If positive anomalies dominate, the curve goes up. In years with negative anomalies, the cumulated curve points down. The last value of the curve corresponds to the actual trend compared with the reference period or the year 1990 (see Fig. 6a, c).

\subsection{Programming tools}

All analyses and visualizations are generated using standard python libraries such as numpy, matplotlib, scipy, basemap, netcdf4 on the PIK computational cluster (E-OBS data) and a local workstation (Potsdam time series).

\section{Results and discussions}

The initial analyses in the previous sections were intended to illustrate that some findings can be derived from combinations of the datasets of a single station, surface parameters in a gridded dataset and weather-types for Europe. In the following paragraphs, the approach is expanded. The aim is to understand the following: (1) changes in weather-type sequences and (2) their possible influence on the long-term change of seasonal temperature and precipitation patterns in Europe.

\subsection{Weather-type sequences}

Using network graph visualization techniques, long-term analyses of Hess and Brezowsky (HB) weather-type sequences provide insights into the multi-dimensionality of the changes including nodes (patterns) and edges (transition) frequency characteristics. Figure 4 shows the circular arrangement of the 30 different HB weather-types, described, e.g. in James (2007). No particular order was chosen. The size of the nodes indicates the mean occurrence frequency and the colouration is according to the longest consecutive episode in days (only summer-half year). The past conditions (1961-1990) are represented in Fig. 4a and the recent condition (1989-2018) in Fig. 4b. At first glance, some known facts are visible: The most frequent weathertype is Cyclonic Westerly (WZ), followed by Zonal Ridge across Central Europe (BM) and Trough-like circulation patterns (TRM, TRW). Moreover, lines between the nodes indicate the frequency of transition between HB weathertypes. The thickness of the lines denotes how often those transitions were encountered. Comparing the two graph properties, structural shifts in the node size (frequency of occurrence), the node colouration (length of periods) and line widths are found to be well pronounced. A possible linkage between the long-term frequency change of the new dominate weather-types over Europe and the enhanced seasonal predictability has been presented in Hoffmann (2017). As pointed out by Kučerová et al. (2016), analyses based on one single classification should not be generalized or over-interpreted. However, the fact remains that the sequences BM-TRM, BM-TRW and TRW-TRM are currently much more common. Thus, a transition to a more organized structure can be surmised. Most of the previous studies only look at the frequency change of weather-types (e.g. Hoy et al. 2012; Hoy et al. 2013; Fleig et al. 2015) and less at the transitions between the different weather patterns as performed here. 

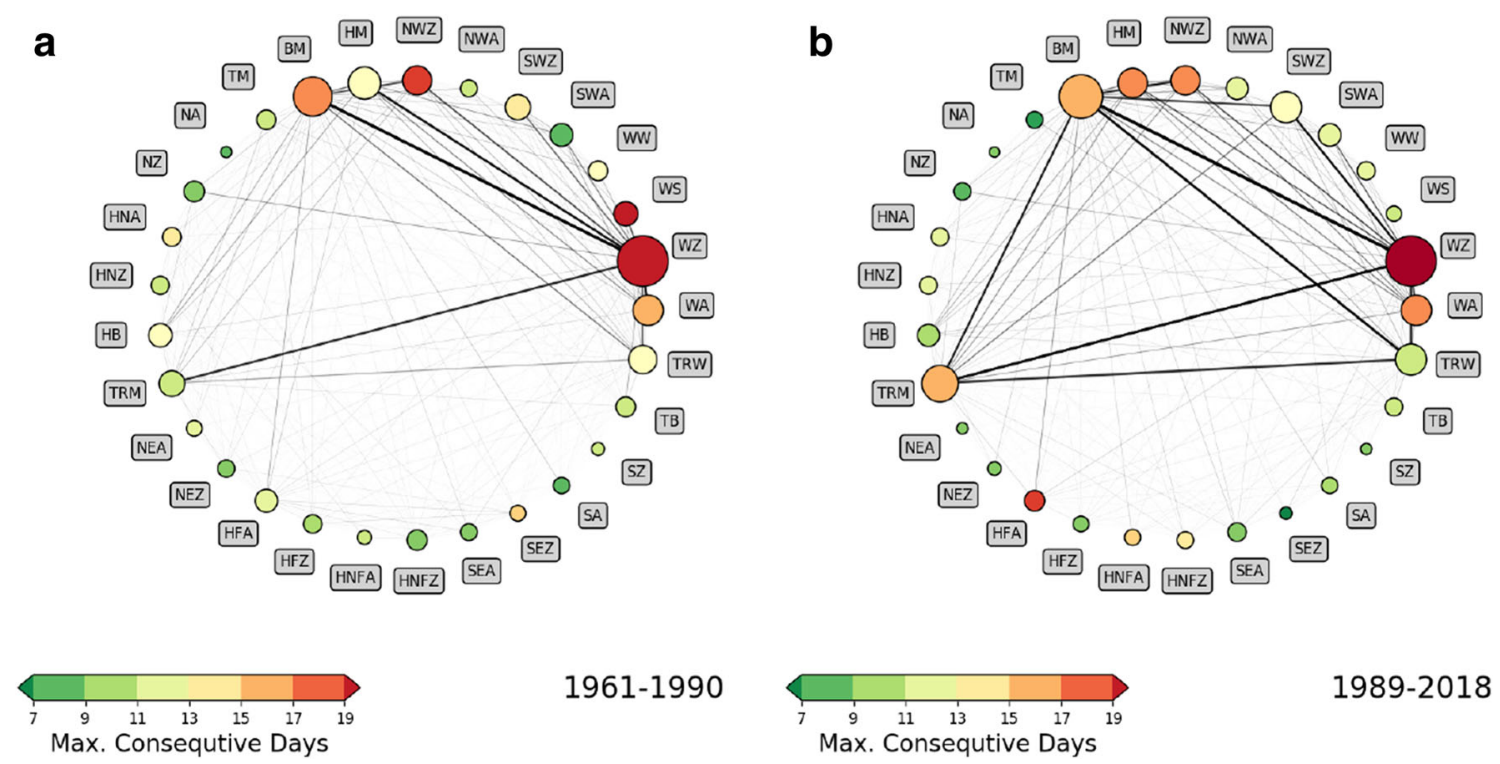

$1961-1990$

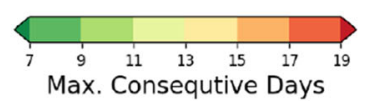

$1989-2018$

Fig. 4 Circular pattern of European HB weather-type sequences in the summer half-year: 1961-1990 (a) and 1989-2018 (b). The node size represents the averaged frequency, the node colour denotes the maximum consecutive days and the connecting lines (edges) indicate the sequence frequency

\subsection{Composite rainfall patterns}

So far, the assignment of warm/wet/dry to the HB weathertypes has been made according to the conditions at the Potsdam station. But what are the local effects of those weather-types for most of Europe. For selected, extreme-prone and dominant types, the 1961-2018 longterm averaged daily rainfall patterns, derived from EOBS data, are depicted in Fig. 5. Focusing on Central Europe (Austria, Croatia, the Czech Republic, Germany, a

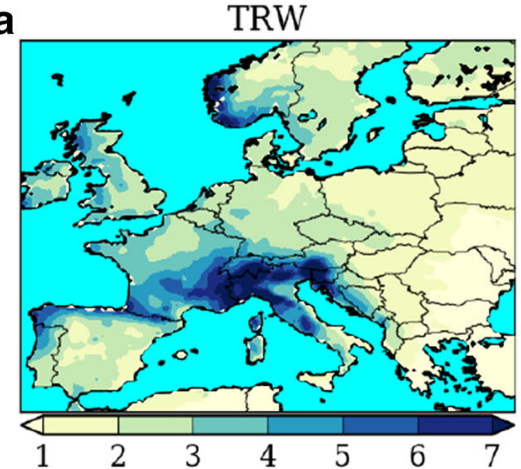

d

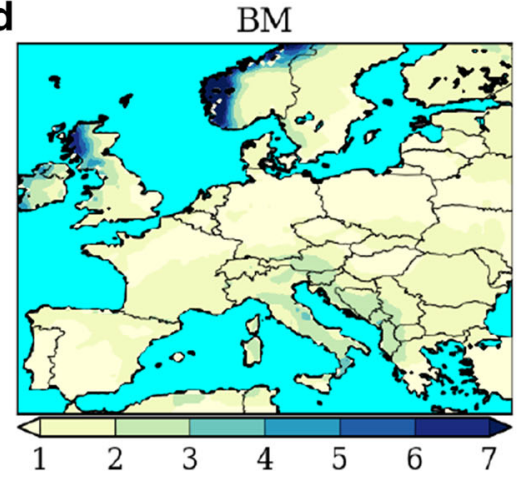

b

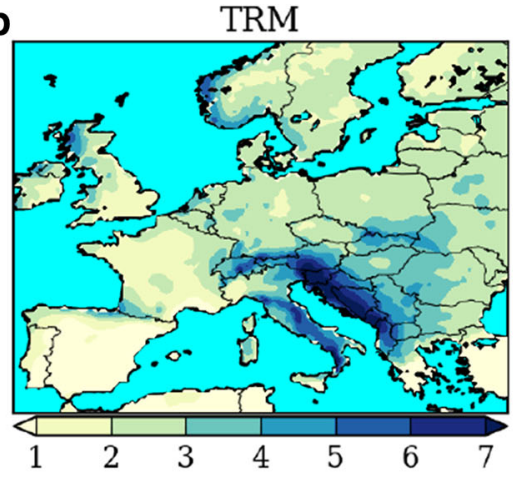

e

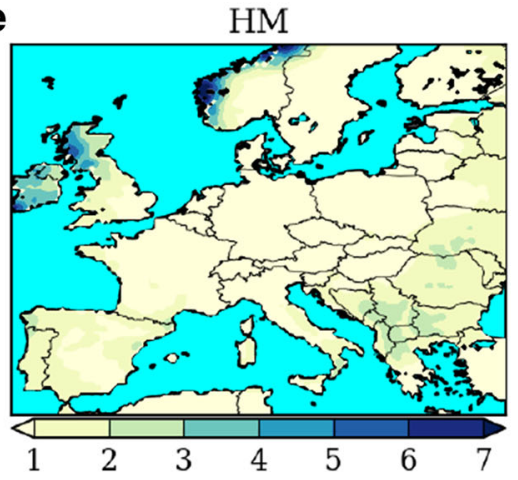

C

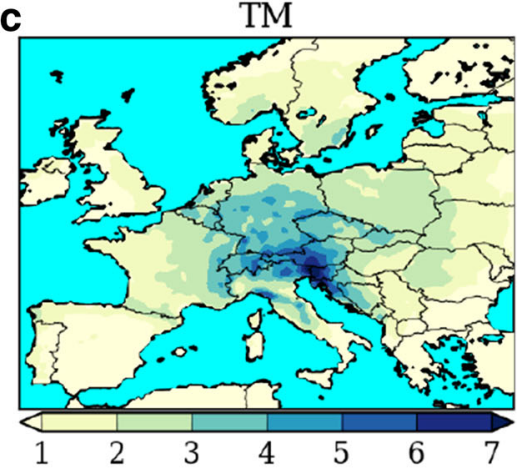

f

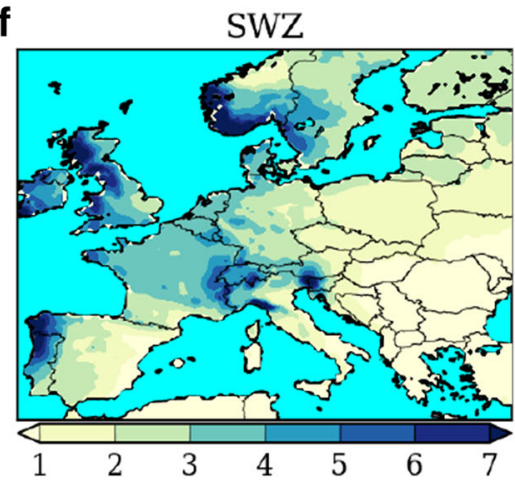

Fig. 5 European composite rainfall patterns from 1961 to 2018 for selected HB weather-types given in mm/day: TRW (a), TRM (b), TM (c), BM (d), HM (e) and SWZ (f) 
Hungary, Poland, Slovakia, Slovenia, Switzerland), the highest amounts of average daily rainfall $(4-5 \mathrm{~mm} /$ day $)$ occur in conjunction with Low pressure over Central Europe (TM) or Trough over Central Europe (TRM). However, much higher intensities (> $7 \mathrm{~mm} /$ day) occur along the Adriatic coast from Croatia and Slovenia to Italy. High over Central Europe (HM) and Zonal Ridge across Central Europe (BM) belong to the driest HB weathertypes in Central Europe but can also favour heavy and permanent rainfall situations over the Mediterranean area and the southern Alps. However, such situations are poorly represented by composite patterns. Please note that the values of less than $10 \mathrm{~mm} /$ day are much lower compared individual events of more than $100 \mathrm{~mm} /$ day because only long-term daily means across seasons are shown. The seasonal representation of each weather-type can be much stronger.

\subsection{Changes on the local scale}

Every HB weather-type can be characterized locally by the long-term monthly mean meteorological variables (Fig. 5), respectively. Due to long-term observed changes in weathertype sequences (Fig. 4), a possible dynamical part of the past climate change signal for seasonal temperature and precipitation can be estimated.

a
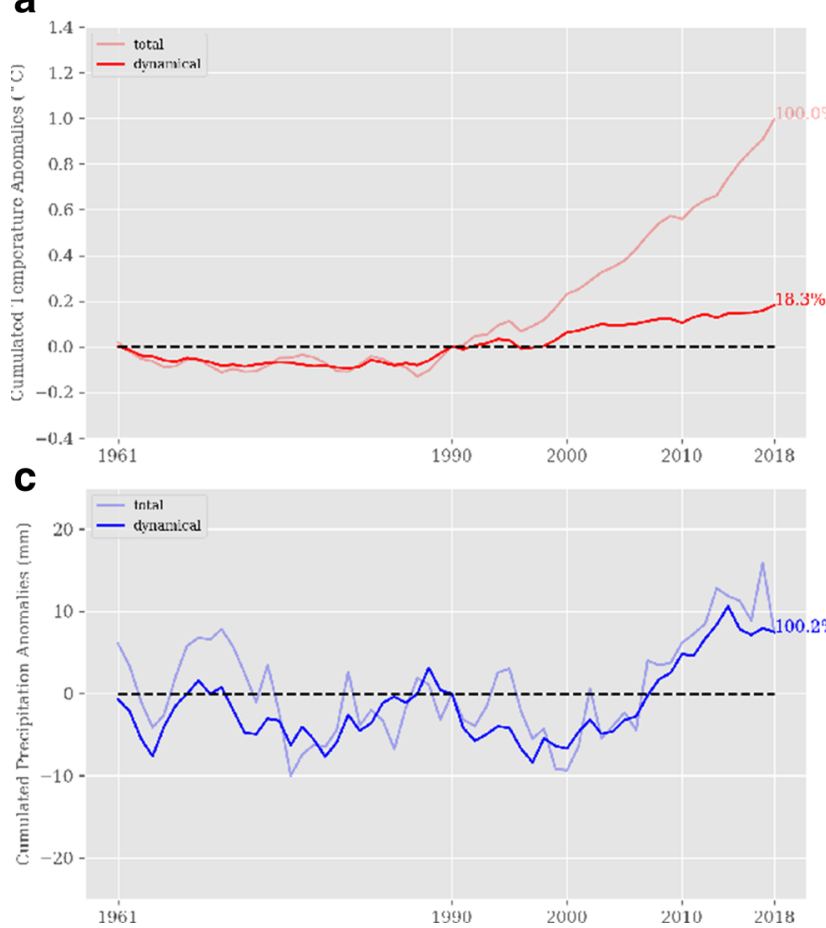

Fig. 6 Left column: Potsdam time series of cumulated anomalies from 1961 to 2018 related to $1961-1960$ of the annual mean temperature (a) and the annual precipitation (c): total (light) and dynamical (bold)
As mentioned in Chapter 3 (Methods), we apply this approach to the data of the Potsdam station in order to separate or decouple the dynamical component from the entire climate change signal. Figure 6 shows the allocation matrix of the long-term mean meteorological conditions temperature (b) and precipitation (d) for each $\mathrm{HB}$ weathertype and month. The highest monthly mean temperature is reached in August if a South Cyclonic (SZ) prevails with $22.8^{\circ} \mathrm{C}$ and the coldest one is High Scandinavia-Iceland, Ridge C. Europe (HNFA) with $-8.2{ }^{\circ} \mathrm{C}$ in December. The highest amount of monthly mean rainfall occurs during Low Pressure over Central Europe (TM) in July with 9.5 $\mathrm{mm} /$ day. In contrast to that, weather-types with a High Pressure over Central Europe (HM) or a Zonal Ridge across Central Europe (BM) represent the driest conditions ( $<1.0 \mathrm{~mm} /$ day). This stationary information are used to generate two analogous daily time series for temperature and precipitation. Only dependent on the date (month) and weather-type, the corresponding value for each day is extracted from the table. In order to improve the comparison between the total and the dynamical part, annual and seasonal mean values are calculated. Due to the strong interannual variability in the data, the focus is on the cumulated anomalies.

Figure 6a depicts the cumulative temperature anomalies time series of the total (light red) and the dynamical b

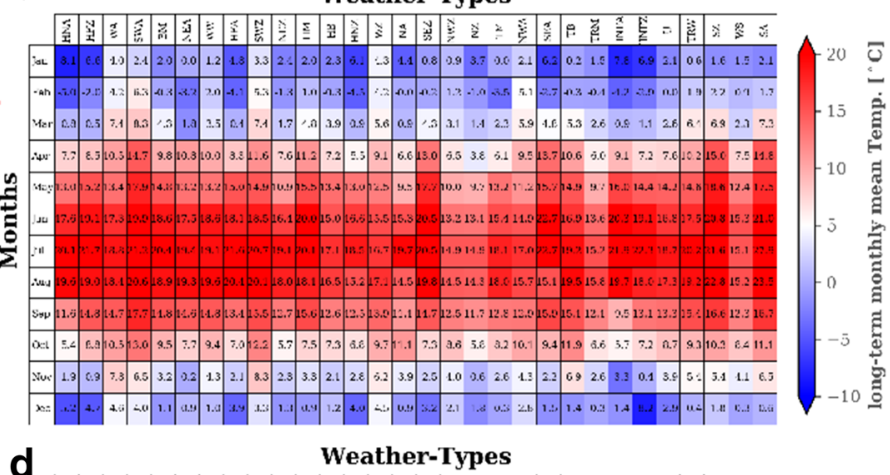

d

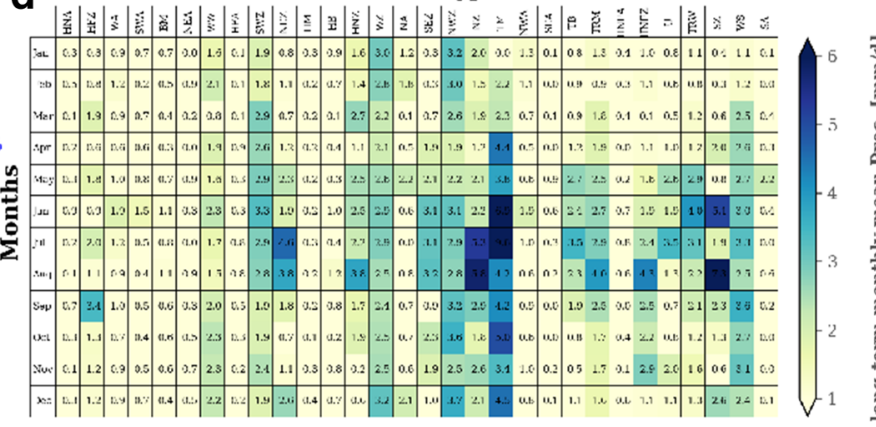

component. Right column: 1961-2018 long-term monthly mean temperature (b) and precipitation (d) per HB weather-types at Potsdam. [seasonal: Fig. 13] 
(dark red) component. The comparison of the two temperature evolutions shows a strong divergence. While the total temperature rises by almost $+1.0^{\circ} \mathrm{C}$ since 1990 , the reconstructed curve which explains the dynamical component of the climate change signal only reaches about $+0.2{ }^{\circ} \mathrm{C}$ (or $18.3 \%$ ). Since both use the same pattern frequency development, it is concluded that most of the long-term changes can be attributed to the fact that the patterns themselves became warmer, i.e. the increase of $1^{\circ} \mathrm{C}$ has mainly thermodynamical or energetic causes. The results for every season are shown in the Supplementary Material Fig. 13. The highest contribution of more than $20 \%$ is found in summer (b) and winter (d). Heat waves, for instance, are a combination of both, the dynamical and the energetical part. In autumn (c), where the temperature rise is much weaker compared with other seasons, the dynamical contribution is even slightly negative.

A similar comparison has been carried out for the two annual precipitation time series of cumulative anomalies. It is striking that, compared with the temperature analysis, hardly any major systematic discrepancies between the total (light blue) and the dynamical (dark blue) part can be found. The well visible increase in the cumulative anomalies since 2000 is on the order of $10 \mathrm{~mm}$. It is larger than the natural variability and it occurs in both time series. Recent long-trend analyses of precipitation in the Rhine basin by Murawski et al. (2018) have shown that, unlike temperature developments, frequency changes of weather patterns play a fundamental role. While the year 2017, clearly exhibited a higher precipitation amount than the reference period level (1961-1990) - rise in the cumulative chart - in 2018 it dropped significantly. This was the driest year to date. From the comparison of the total and dynamical component in 2017, we are able to identify a large gap between the both parts. The dynamical component - or the frequency of weather-types - alone cannot explain the unusual large amount of rainfall in the north-eastern part of Germany. Later in the Chapter (Extreme seasons), we will revisit the rainfall situation in summer 2017. Further analyses on seasonal behaviour can be found in the Supplementary Material Fig. 13. The tendency towards a dryer spring season as well as increasing summer rainfall in eastern Germany between 1990 and 2018 can be well explained by dynamical changes over Europe.

\subsection{NAO vs weather-types}

Before addressing the changes on the continental scale, the linkage between the phase of the North Atlantic Oscillation (NAO) and the prevailing HB weather-types will be studied. The question is: Do we deal with an underlying change that can be attributed to the long-term development of hemispheric circulation? For this purpose, it was analyzed which HB weather-types were in conjunction with specific amounts of the NAO Index (Barnston and Livezey 1987), which essentially separate east-west and north-south oriented flows. In order to illustrate that the observed change of the seasonal precipitation in summer, which occurs in Potsdam since about 2000, is mainly drive by dynamics, Fig. 7a depicts an accordant long-term change of NAO using seasonally cumulated anomalies related to 1961-1990. A similar timing of the trend change in summer around 2000 emerges. Moreover, there is a marked seasonality with wintertime conditions (blue) tending to have positive NAO phases and summer time conditions (red) tending towards negative NAO phases. NAO trends for spring and autumn are much weaker or not detectable. The prevailing negative phase of NAO is often associated with weather-types such as TM or TRM (Low pressure or Trough over Central Europe). Figure $7 \mathrm{~b}$ shows the contributing weather-types per NAO bin, similar to Fig. 2. These patterns are in conjunction with the highest amount a

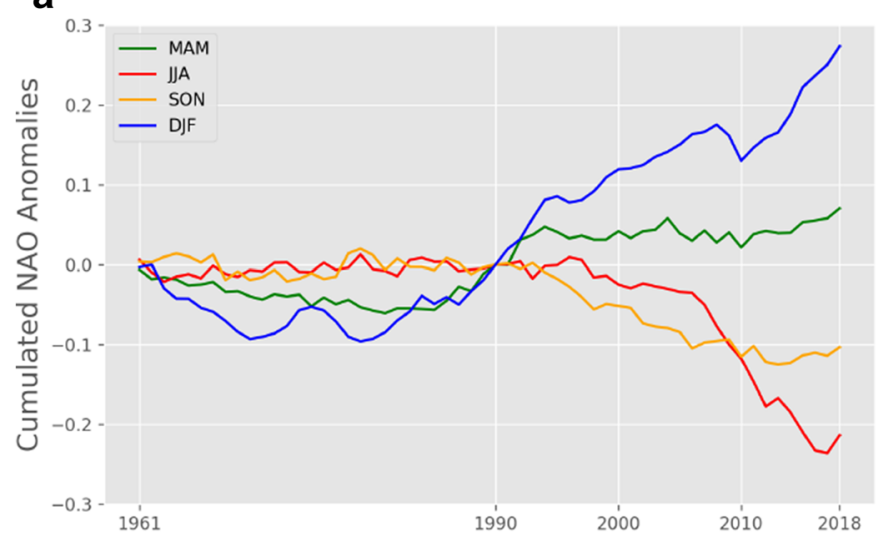

b

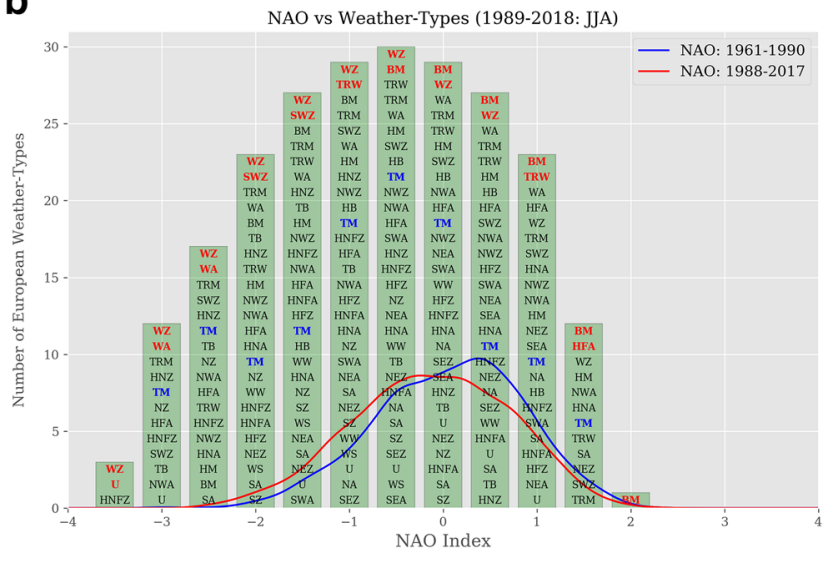

Fig. 7 a Seasonal time series of cumulated NAO anomalies from 1961 to 2018 related to 1961-1960. b Histogram of the contributing weather-types per NAO phase interval in summer for the period 1989-2018. Lines denote the shift in the probability density function 
of rainfall in Potsdam and the north-eastern part of Germany as well. The lower the NAO phase in summer, the higher the frequency of potentially very wet weather-types as well as the total amount of rainfall in Central Europe. In the positive phase of NAO, on the other hand, those weather-types occur less frequent. In Fernández-González et al. (2012), the connection between long-term trends in NAO, Lamb weather-types and precipitation in Spain was analyzed. That study found that the increasing positive phase in winter is associated with an increase in dry and anticyclonic weather.

\subsection{Changes on the continental scale}

HB weather-types aim to be valid for the entire Europe. The application of the approach to decouple the dynamical part from the total annual mean temperature and precipitation is given in Fig. 8. As already found in the local analysis, a stronger connectivity between weather-types and rainfall patterns is also apparent on the continental scale in most of the regions. The maps in Fig. 8 show cumulative anomalies from 1961 to 2018 averaged over a recent 5year period 2014-2018 for temperature (a) and precipitation (b). The patterns for the dynamical component are shown in Fig. 8 (right column). As already found on the local scale, most of the long-term temperature changes are of thermodynamical nature in major parts of Europe. The dynamical fraction is on the order of less than $\pm 0.5{ }^{\circ} \mathrm{C}$ compared with the factual temperature trend of about $+1{ }^{\circ} \mathrm{C}$ or more since 1990 across nearly all of Europe. The longterm changes in the rainfall patterns in Fig. 8 show much higher similarities $(\mathrm{SSIM}=0.74)$ between the total and the dynamical part. Most of the features can be found in both, such as the maximum over the Alps and the minimum over Portugal. Larger differences can be identified in South-West Germany. A possible cause is the occurrence of convective rain events. Further analyses on seasonal patterns are given a

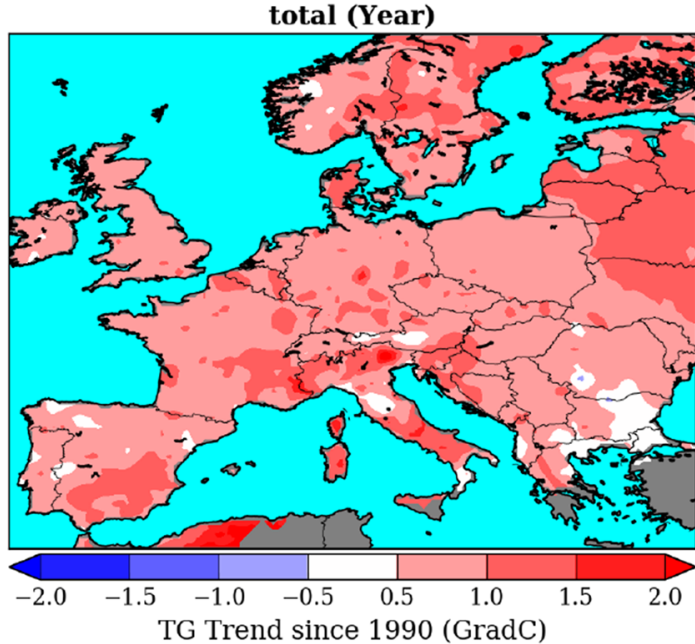

b

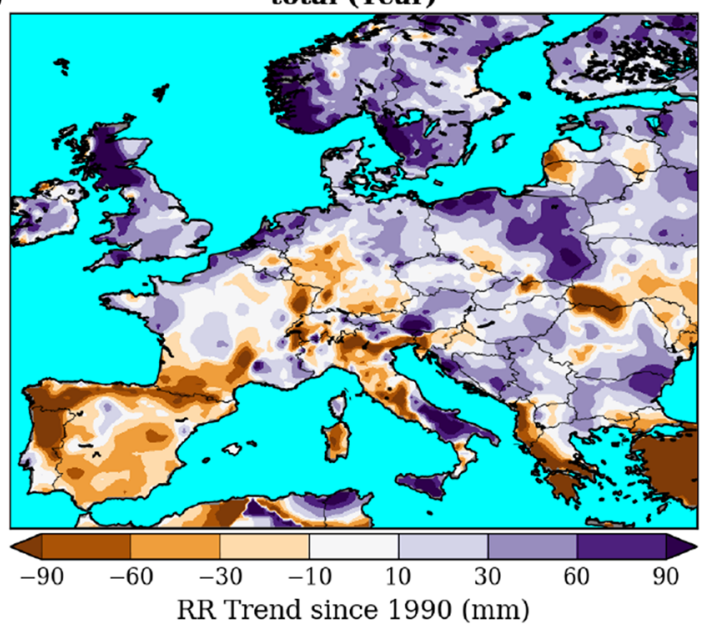

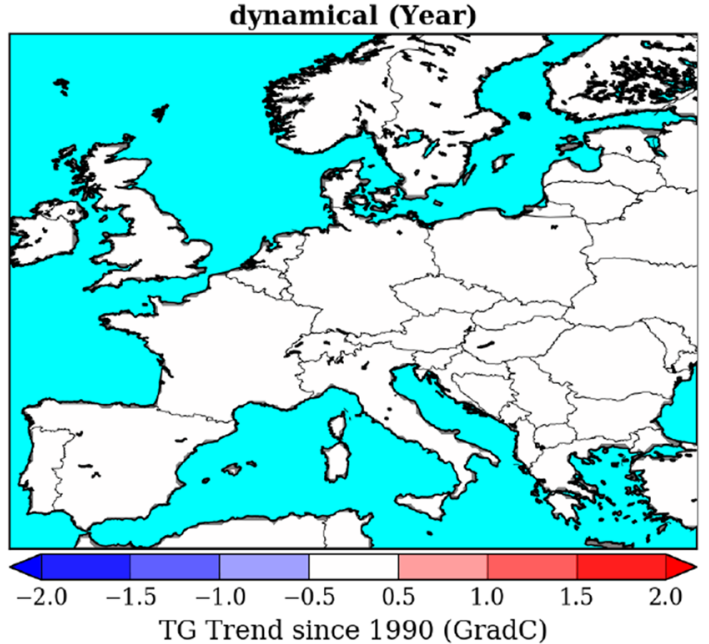

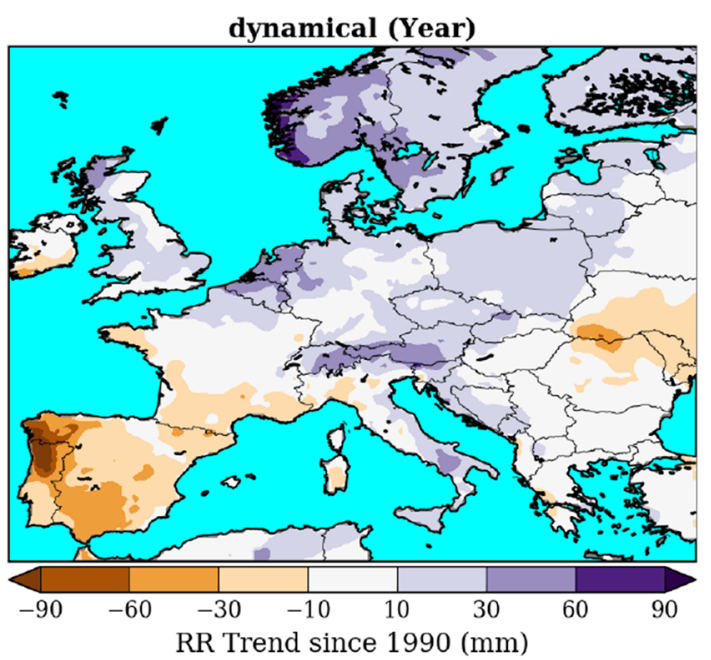

Fig. 8 European maps of the cumulative anomalies from 1961 to 2018 related to 1961-1990 of annual mean temperature (a) and annual precipitation (b) averaged over 2014-2018: total (left column) and dynamical (right column) part. [seasonal: Fig. 14] 

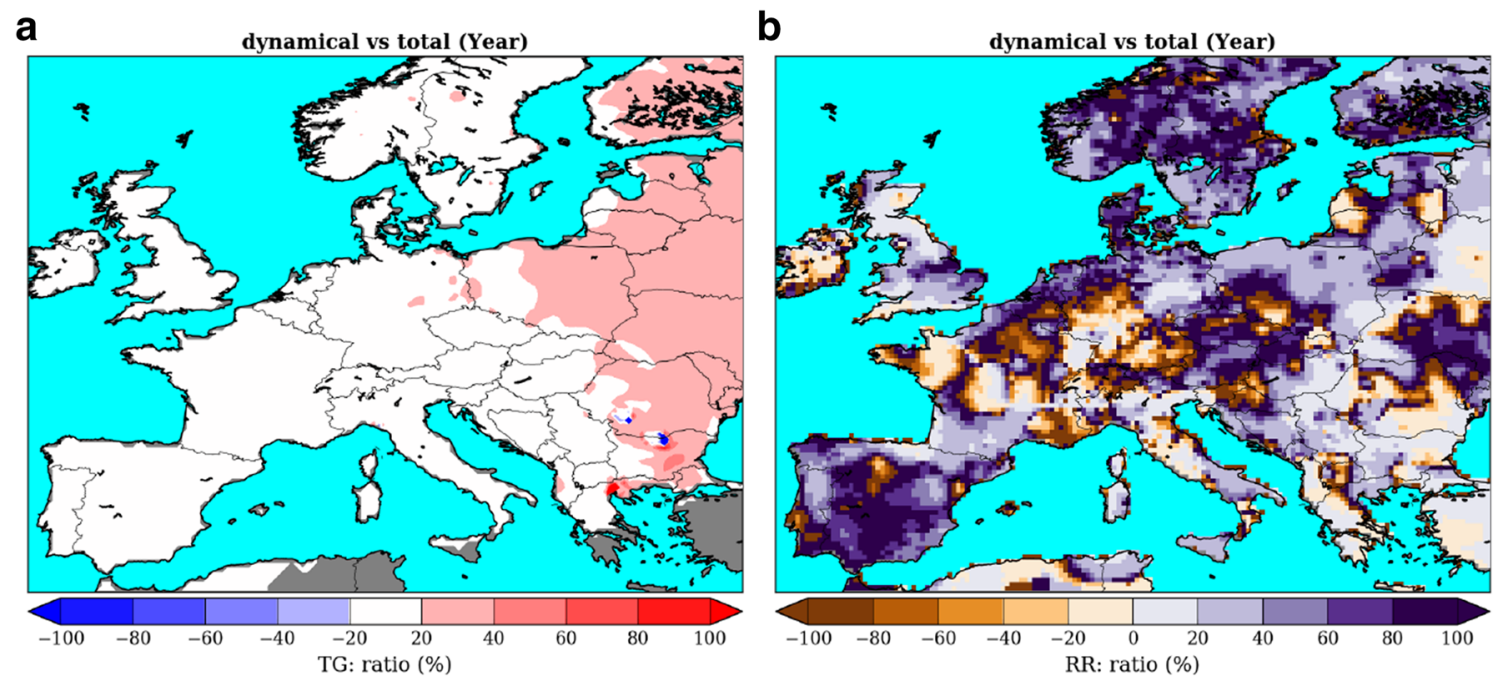

Fig. 9 European maps of the percentage between the dynamical and total component: annual mean temperature (a) and annual precipitation (b). [seasonal: Fig. 15]

in the Supplementary Material. Figure 14 indicates that the dynamical part of the temperature rise across the seasons is lower the $\pm 0.5{ }^{\circ} \mathrm{C}$ in most of the regions. Higher amounts are only found over the Balkans. In contrast, many of the long-term changes of seasonal rainfall patterns can be explained by dynamical factors. Areas showing an increasing (purple) and an decreasing (orange) trend in the total and dynamical patterns are located in the same areafor instance the orange areas ranging from South-West to Central Europe or the occurrence of increasing trends on both components (total and dynamical) over the northern part of Mediterranean.

The share (in \%) of the dynamic component on the total of the observed annual temperature and precipitation change pattern is given in Fig. 9. The contribution is larger than $20 \%$ just in Eastern Europe. The seasonal patterns in the Supplementary Materials in Fig. 15 depict a meridional

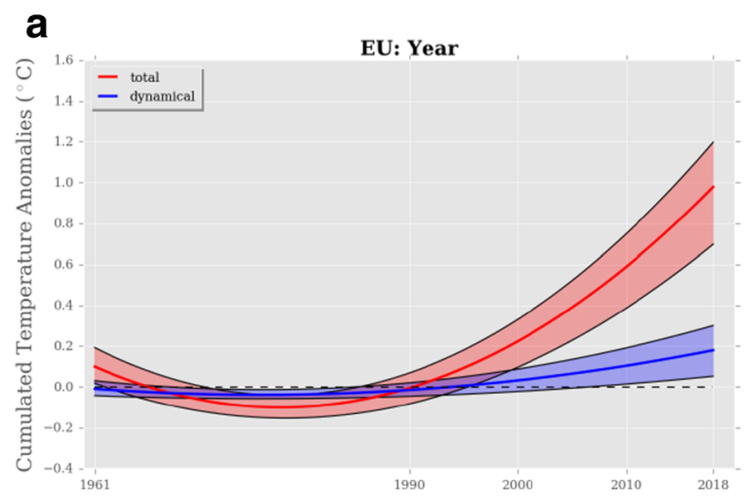

Fig. 10 Temporally cumulated annual mean temperature anomalies for the total (red) and the dynamical component (blue) over the European continent (a). Temporally cumulated annual precipitation anomalies for the total (red) and the dynamical component (blue) over orientation in summer (c) and a predominantly zonal orientation in winter $(\mathrm{g})$. A linkage to the prevailing positive NAO phase in winter and the prevailing negative NAO phase in summer is likely. The latter favours the occurrence of meridional wave-like circulation patterns. Negative values are only found over the Iberian peninsula in autumn. The contribution concerning precipitation is much larger but also more heterogeneous. Areas with strong positive values surround areas with highly negative anomalies, particularly in summer over the south-western part of Germany (d). This is a region of intense convective rain events in recent years. There, the dynamic component is even higher than the total.

The temporal evolution of the cumulated anomalies of the annual mean temperature (a) and the annual precipitation (b) over all of Europe is given in Fig. 10, similar to Fig. 6 for Potsdam, by calculating the mean as well as 10th and 90th percentile of the grid cells for

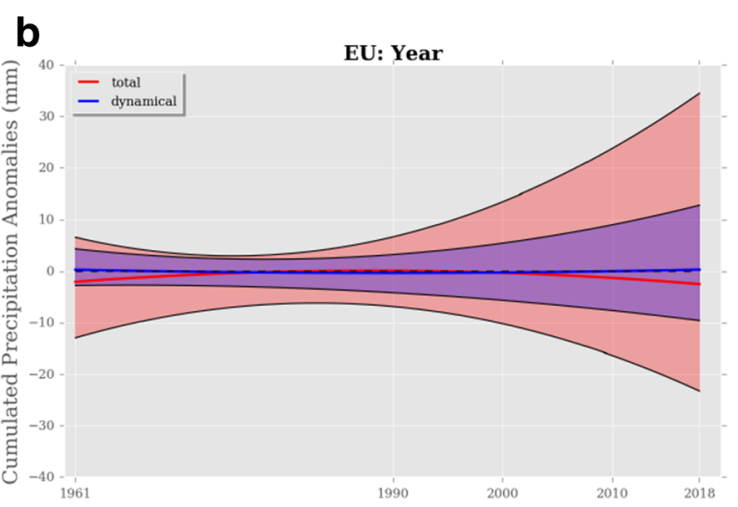

the European continent $(\mathbf{b})$. The shaded area is represented by the 10th and 90th percentile and solid line by the mean, respectively. The lines were fit by a second-order polynom. [seasonal: Fig. 16] 
each year. The lines are finally smoothed by a secondorder polynomial fit. The bands for the total (red) and the dynamical component (blue) indicate an area which encompasses $50 \%$ of the values.

In about $50 \%$ of the grid cells over the European land mass, the temperature increase since 1990 amounts to about $1{ }^{\circ} \mathrm{C}$ (Fig. 10a). Only $25 \%$ of the grid cells show values lower than $0.7^{\circ} \mathrm{C}$. The dynamical share is much lower and smaller than $0.3^{\circ} \mathrm{C}$. After about 2000 , both components are clearly separated.

Regarding temporal changes of cumulated anomalies in annual precipitation over Europe, we can identify two branches of increasing and decreasing trends for both the total (red) and dynamical (blue) component (Fig. 10b). The total change range from about -35 to $+35 \mathrm{~mm}$ after 1990 . The dynamical component explains a smaller value range from about -10 to $+15 \mathrm{~mm}$. However, the portion is the order of $50 \%$ for regions with increasing (upper branch) and about $30 \%$ for regions with decreasing tendency (lower branch).

The seasonal characteristics are given in the Supplementary Material (Fig. 16. The highest share of the dynamical component for the temperature signal is apparent in summer $[0.0 \ldots 0.4]{ }^{\circ} \mathrm{C}$ and the lowest in autumn $[-0.1 \ldots 0.2]{ }^{\circ} \mathrm{C}$. The highest share of explained climate change signal for precipitation by the dynamical component is found in spring for mainly the dry branch and summer mainly for the dry and wet branch.

The sub-regional perspective of the long-term annual precipitation changes is given in Fig. 11, where we distinguish between Northern Europe (left) lat $>55^{\circ} \mathrm{N}$, Central Europe (middle) $45^{\circ} \mathrm{N} \leq 1 \mathrm{at} \leq 55^{\circ} \mathrm{N}$ and Southern Europe (right) lat $<45^{\circ} \mathrm{N}$ for a given latitude range. The meaning of the lines is analogue to Fig. 16. In almost all subregions, the dynamical part (blue band) reflects the trend direction of the total part (red band): Northern Europe (NE) increasing and Southern Europe (SE) decreasing. In Central Europe, trends in two directions are evident. However, the decreasing branch can almost completely be explained by the dynamical part. Otherwise, the proportion is clearly well below $50 \%$ for the annual totals. The seasonal perspectives of the long-term precipitation changes for the different subregions are given in the Supplementary Material (Fig. 17). Further overlapping branches can be identified in NE for increasing precipitation in spring and in summer and in CE for decreasing precipitation in spring and both directions in summer. The highest portion in SE is found in autumn.

\subsection{Extreme seasons}

By computing the dynamical component for only one season, we are able to estimate the thermodynamical (total minus dynamical) component for both temperature but most of all precipitation. A good example is the summer 2017. It has been characterized by a series of extreme rainfall events over the north-eastern part of Germany and long-lasting dry and very warm conditions in the southern part of Europe as reported in WMO (2017). The total amount within the period June, July and August locally reached more than 400 $\mathrm{mm}$. In 2018, this was the total rainfall of the entire year! In order to find out to what extent the extreme wet summer 2017 was triggered by dynamical features, we applied our approach to decouple the weather-type-related part to one individual season.

Figure 12 shows the comparisons between the total and the dynamical patterns for the summer mean temperature (a, b, c) and the total rainfall (d, e, f) of 2017. The summer mean temperature patterns indicate high similarities and the differences are on the order of $2{ }^{\circ} \mathrm{C}$ or less. Negative anomalies (dynamical>total) are found over the northern part of Europe and positive anomalies in the South. Overall, the temperature conditions in the summer of 2017 over most parts of Europe could be well mapped by the prevailing weather-types and dynamical factors.

In contrast to that, the difference pattern (total minus dynamical) of seasonal rainfall shows one prominent a

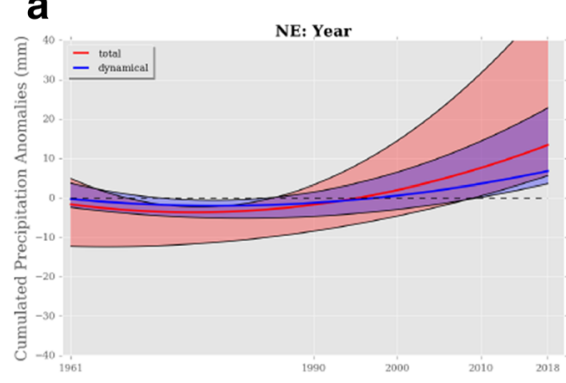

b
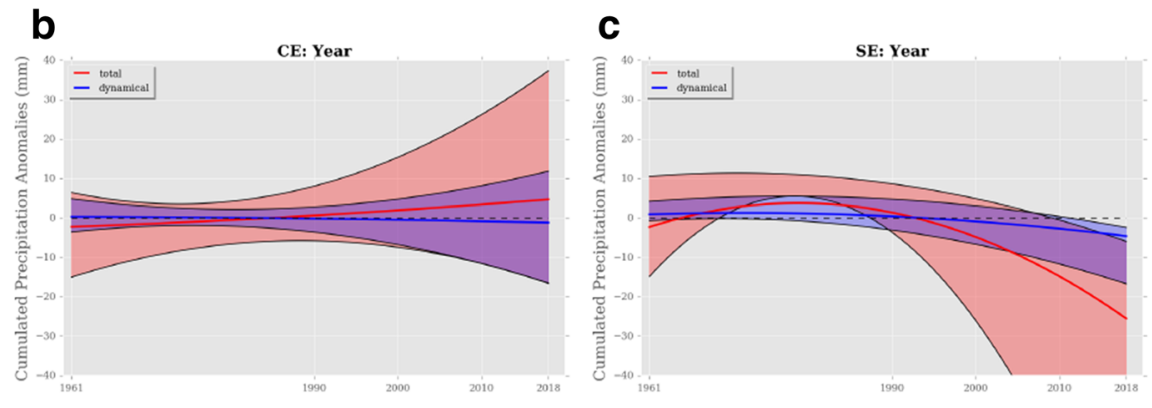

Fig. 11 Temporally cumulated annual precipitation anomalies for the total (red) and the dynamical component (blue) over the European subregions: a Northern Europe (NE) lat $>55^{\circ} \mathrm{N}$ b Central Europe (CE) $45^{\circ} \mathrm{N} \geq \mathrm{lat} \leq 55^{\circ} \mathrm{N}$ and $\mathrm{c}$ Southern Europe (SE) lat $<45^{\circ} \mathrm{N}$. The shaded area is represented by the 10th and 90th percentile and solid line by the mean, respectively. The lines were fitted by a second-order polynomial. [seasonal: Fig. 17] 

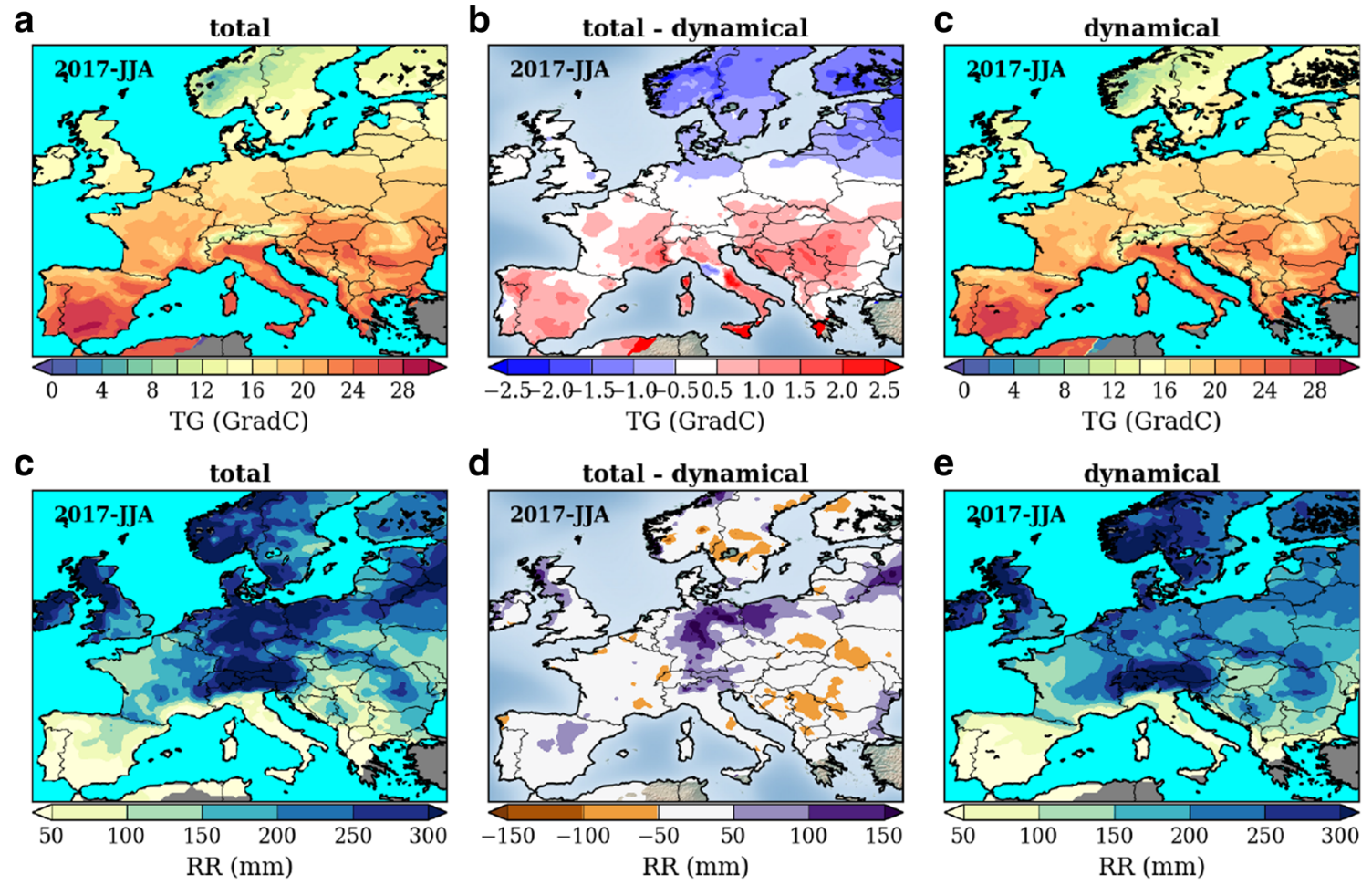

Fig. 12 Seasonal patterns of summer 2017 for the mean temperature $(\mathbf{a}, \mathbf{b}, \mathbf{c})$ and the total precipitation $(\mathbf{d}, \mathbf{e}, \mathbf{f})$ : total (a, d), dynamical (c, f) and total minus dynamical $(\mathbf{b}, \mathbf{e})$

feature over Central Europe with deviations amounting to more than 100-150 $\mathrm{mm}$. That can be interpreted as the residual signal (thermodynamical) between the total and the dynamical component. Another example is given in the Supplementary Material (Fig. 18) for the dry summer of 2003. It shows temperature differences between the total and the dynamical component larger than $1.5^{\circ} \mathrm{C}$ in Southern and Central Europe. This is the portion of the energy share that cannot explained by the prevailing weathertypes characteristics. However, the total rainfall pattern in the summer of 2003 can be rather well explained by the dynamical component.

\section{Conclusion}

An assessment and diagnosis of the regional climate change should include, first and foremost the long-term analysis of derived climate indicators (e.g. Hoffmann et al. 2018) as well as categorical data on large-scale weather patterns (e.g. Hoffmann 2017). Through a suitable combination of large-scale causes (weather-types) and small-scale effects (local temperature and precipitation), relationships can be established and transferred to address further research questions. In this paper, we pose and answer the question: How large is the dynamical share of the observed change in seasonal temperature and precipitation patterns over Europe? The data used are long-term, publicly available and the methodology is straightforward. A general transferability of the method to climate simulations and their evaluation is also conceivable. The largest sources of uncertainty in climate projections can be linked to atmospheric dynamics (e.g. Shepherd 2014).

Every point in Europe is characterized by two daily properties - local and regional (e.g. Kyselý 2008). The regional property consists of categories of weather-types (here 30). These are defined for the entire area and only long-term changes in frequency, duration and sequence are possible. The translation into a meteorological effect at each location is achieved by inserting values from a derived climatological assignment table by weather-type and month. This includes the long-term monthly mean values of meteorological variables (temperature $\left({ }^{\circ} \mathrm{C}\right)$ and precipitation $(\mathrm{mm} /$ day)) when a prevailing weather-type occurs in a given month. Although there may be strong daily deviations from the respective average, these are minimized due to a larger temporal aggregation. This is well suited to study long-term changes in seasonal and annual temperature or rainfall patterns. By using the respective mean values only, long-term changes are causing the changed sequence of weather patterns. High similarities to the total climate change signal can be attributed to a higher share of the dynamical component. An attribution study by Fleig et al. (2015) used a similar methodology to decouple synoptic 
circulation changes from monthly climatic trends. Finally, trend ratios were calculated to identify the share of the dynamical change on the observed trends. The relative influence is strongly varying between regions, months and climate variables. However, the effect is more pronounced in the north-western part of Europe where we also found the highest similarity between the total and the dynamical share. It should be kept in mind, that the methodology based on one weather-type classification should not be overinterpreted, as recommended by Kučerová et al. (2016). We share this view when referring solely to the trends of frequencies and duration of weather-types. The decoupling of the dynamic share, as suggested here, is based on the sum of many weather-type transitions over years and the translation into meteorological quantities. Therefore, a possible misallocation in the classification scheme of similar weather-types has only a small meteorological effect.

The long-term changes of seasonal rainfall patterns in Europe are tightly linked to changes in dynamics. The increasing spring drought in many parts of Europe (Hoy et al. 2016; Hänsel et al. 2019) can be largely explained by dynamical factors because rather drier weather patterns dominate. Furthermore, in summer, most of the regions exhibit a trend direction or decadal variation which is confirmed by the dynamical share. In regions where the sign is opposite (e.g. South-West Germany), an accumulation of local and intense rainfall events under rather drier weathertype conditions is assumed. Even two subsequently very dry years (2018 and 2019) in Central Europe cannot compensate the above average seasonal rainfall of previous years.

The key message of this paper is that changing rainfall patterns are largely caused by dynamical changes, whereas the observed warming cannot alone be explained by a higher frequency and duration of warmer weather-types.

Acknowledgements The authors thanks the data providers for the open access and the high-quality standard of the data: the German Meteorolgical Service (DWD) and the European Climate Assessment \& Dataset (ECA\&D) team.

Funding Open Access funding provided by Projekt DEAL.

Open Access This article is licensed under a Creative Commons Attribution 4.0 International License, which permits use, sharing, adaptation, distribution and reproduction in any medium or format, as long as you give appropriate credit to the original author(s) and the source, provide a link to the Creative Commons licence, and indicate if changes were made. The images or other third party material in this article are included in the article's Creative Commons licence, unless indicated otherwise in a credit line to the material. If material is not included in the article's Creative Commons licence and your intended use is not permitted by statutory regulation or exceeds the permitted use, you will need to obtain permission directly from the copyright holder. To view a copy of this licence, visit http:// creativecommonshorg/licenses/by/4.0/.

\section{References}

Barnston AG, Livezey RE (1987) Classification, seasonality and persistence of low-frequency atmospheric circulation patterns. Mon Weather Rev 115(6):1083-1126. https://doi.org/10.1175/15200493(1987) $115<1083:$ csapo > 2.0.co;2

Cahynová M, Huth R (2009) Enhanced lifetime of atmospheric circulation types over Europe: fact or fiction? Tellus A 61(3):407416. https://doi.org/10.1111/j.1600-0870.2009.00393.x

Casanueva A, Rodríguez-Puebla C, Frías MD, González-Reviriego N (2014) Variability of extreme precipitation over Europe and its relationships with teleconnection patterns. Hydrology and Earth System Sciences 18(2):709-725. https://doi.org/10.5194/hess-18709-2014

Coumou D, Robinson A, Rahmstorf S (2013) Global increase in record-breaking monthly-mean temperatures. Clim Chang 118(3):771-782. https://doi.org/10.1007/s10584-012-0668-1

Coumou D, Petoukhov V, Rahmstorf S, Petri S, Schellnhuber HJ (2014) Quasi-resonant circulation regimes and hemispheric synchronization of extreme weather in boreal summer. PNAS 111(34):12,331-12,336. https://doi.org/10.1073/pnas.1412 797111

Coumou D, Lehmann J, Beckmann J (2015) The weakening summer circulation in the northern hemisphere mid-latitudes. Science. https://doi.org/10.1126/science.1261768

Coumou D, Capua GD, Vavrus S, Wang L, Wang S (2018) The influence of arctic amplification on mid-latitude summer circulation. Nat Commun 9(1). https://doi.org/10.1038/s41467-018-05256-8

Davini P, D'Andrea F (2016) Northern hemisphere atmospheric blocking representation in global climate models: twenty years of improvements? J Clim 29(24):8823-8840. https://doi.org/10. 1175/jcli-d-16-0242.1

Donat MG, Leckebusch GC, Pinto JG, Ulbrich U (2009) Examination of wind storms over Central Europe with respect to circulation weather types and NAO phases. International Journal of Climatology, pp n/a-n/a. https://doi.org/10.1002/joc.1982

Fernández-González S, del Río S, Castro A, Penas A, FernándezRaga M, Calvo AI, Fraile R (2012) Connection between NAO, weather types and precipitation in León, Spain (19482008). International Journal of Climatology, pp n/a-n/a. https://doi.org/10.1002/joc.2431

Fleig AK, Tallaksen LM, James P, Hisdal H, Stahl K (2015) Attribution of European precipitation and temperature trends to changes in synoptic circulation. Hydrol Earth Syst Sci 19(7):3093-3107. https://doi.org/10.5194/hess-19-3093-2015

Gilbert R (1987) Statistical methods for environmental pollution monitoring. Wiley, New York

Hänsel S, Ustrnul Z, ŁUpikasza E, Skalak P (2019) Assessing seasonal drought variations and trends over Central Europe. Adv Water Resour 127:53-75. https://doi.org/10.1016/j.advwatres.2019.03. 005

Hattermann FF, Wortmann M, Liersch S, Toumi R, Sparks N, Genillard C, Schröter K, Steinhausen M, Gyalai-Korpos M, Máté K, Hayes B, del Rocío Rivas López M, Rácz T, Nielsen MR, Kaspersen PS, Drews M (2018) Simulation of flood hazard and risk in the danube basin with the future danube model. Climate Services 12:14-26. https://doi.org/10.1016/j.cliser.2018.07.001

Hess P, Brezowsky H (1977) Catalog of the general weather situations of Europe 1981-1976. German Meteorological Service

Hoffmann P (2017) Enhanced seasonal predictability of the summer mean temperature in Central Europe favored by new dominant weather patterns. Clim Dyn 50(7-8):2799-2812. https://doi.org/ 10.1007/s00382-017-3772-0

Hoffmann P, Menz C, Spekat A (2018) Bias adjustment for threshold-based climate indicators. Adv Sci Res 15:107-116. https://doi.org/10.5194/asr-15-107-2018 
Hoy A, Sepp M, Matschullat J (2012) Atmospheric circulation variability in Europe and Northern Asia (1901 to 2010). Theor Appl Climatol 113(1-2):105-126. https://doi.org/10.1007/s00704012-0770-3

Hoy A, Schucknecht A, Sepp M, Matschullat J (2013) Large-scale synoptic types and their impact on European precipitation. Theor Appl Climatol 116(1-2):19-35. https://doi.org/10.1007/s00704-013-08 97-x

Hoy A, Hänsel S, Skalak P, Ustrnul Z (2016) The extreme European summer of 2015 in a long-term perspective. International Journal of Climatology 37(2):943-962. https://doi.org/10.1002/joc.4751

Huth R, Beck C, Philipp A, Demuzere M, Ustrnul Z, Cahynová M, Kyselý J, Tveito OE (2008) Classifications of atmospheric circulation patterns. Ann N Y Acad Sci 1146(1):105-152. https://doi.org/10.1196/annals.1446.019

James PM (2007) An objective classification method for Hess and Brezowsky Grosswetterlagen over Europe. Theor Appl Climatol 88:17-42. https://doi.org/10.1007/s00704-006-0239-3

Kornhuber K, Osprey S, Coumou D, Petri S, Petoukhov V, Rahmstorf S, Gray L (2019) Extreme weather events in early summer 2018 connected by a recurrent hemispheric wave-7 pattern. Environmental Research Letters 14(5):054,002. https://doi.org/10.1088/ 1748-9326/ab13bf

Kučerová M, Beck C, Philipp A, Huth R (2016) Trends in frequency and persistence of atmospheric circulation types over Europe derived from a multitude of classifications. International Journal of Climatology 37(5):2502-2521. https://doi.org/10.1002/joc.4861

Kyselý J (2008) Influence of the persistence of circulation patterns on warm and cold temperature anomalies in Europe: analysis over the 20th century. Glob Planet Chang 62(1-2):147-163. https://doi.org/ 10.1016/j.gloplacha.2008.01.003

Lehmann J, Coumou D, Frieler K (2015) Increased record-breaking precipitation events under global warming. Clim Chang 132:501515. https://doi.org/10.1007/s10584-015-1434-y

Molnos S, Petri S, Lehmann J, Peukert E, Coumou D (2017) The sensitivity of the large-scale atmosphere circulation to changes in surface temperature gradients in the northern hemisphere. Earth System Dynamics Discussions, pp 1-17. https://doi.org/10.5194/ esd-2017-65

Murawski A, Vorogushyn S, Bürger G, Gerlitz L, Merz B (2018) Do changing weather types explain observed climatic trends in the rhine basin? an analysis of within- and between-type changes. Journal of Geophysical Research: Atmospheres. https://doi.org/10. 1002/2017jd026654

Nemešová I, Klimperová N (1995) Weather categorization — a useful tool for assessing climatic trends. Theor Appl Climatol 51(12):39-49. https://doi.org/10.1007/bf00865538

Pasini A, Racca P, Amendola S, Cartocci G, Cassardo C (2017) Attribution of recent temperature behaviour reassessed by a neuralnetwork method. Scientific Reports 7(1). https://doi.org/10.1038/ s41598-017-18011-8

Pfahl S, O'Gorman PA, Fischer EM (2017) Understanding the regional pattern of projected future changes in extreme precipitation. Nat Clim Chang 7(6):423-427. https://doi.org/10.1038/nclimate3287

Pfleiderer P, Schleussner CF, Kornhuber K, Coumou D (2019) Summer weather becomes more persistent in a 2 degree world. Nat Clim Chang 9(9):666-671. https://doi.org/10.1038/s41558-0190555-0

Schaller N, Sillmann J, Anstey J, Fischer EM, Grams CM, Russo S (2018) Influence of blocking on Northern European and western russian heatwaves in large climate model ensembles. Environmental Research Letters 13(5):054,015. https://doi.org/10.1088/ 1748-9326/aaba55

Schönwiese CD, Grieser J, Trömel S (2003) Secular change of extreme monthly precipitation in Europe. Theoretical and Applied Climatology 75(3-4):245-250. https://doi.org/10.1007/s00704-0030728-6

Shepherd TG (2014) Atmospheric circulation as a source of uncertainty in climate change projections. Nat Geosci 7(10):703708. https://doi.org/10.1038/ngeo2253

Stucki P, Rickli R, Brönnimann S, Martius O, Wanner H, Grebner D, Luterbacher J (2012) Weather patterns and hydro-climatological precursors of extreme floods in Switzerland since 1868. Meteorologische Zeitschrift 21(6):531-550. https://doi.org/10.1127/09412948/2012/368

Trenberth K (2011) Changes in precipitation with climate change. Clim Res 47(1):123-138. https://doi.org/10.3354/cr00953

Trenberth KE, Fasullo JT, Shepherd TG (2015) Attribution of climate extreme events. Nature Climate Change 5(8):725-730. https://doi.org/10.1038/nclimate2657

Tveito O, Huth R (2016) Circulation-type classifications in Europe: results of the cost 733 action. Int J Climatol 36:2671-2672

Ummenhofer CC, Seo H, Kwon YO, Parfitt R, Brands S, Joyce TM (2017) Emerging European winter precipitation pattern linked to atmospheric circulation changes over the north atlantic region in recent decades. Geophysical Research Letters 44(16):8557-8566. https://doi.org/10.1002/2017g1074188

van den Besselaar EJM, Haylock MR, van der Schrier G, Tank AMGK (2011) A European daily high-resolution observational gridded data set of sea level pressure. J Geophys Res 116(D11). https://doi.org/10.1029/2010jd015468

van den Besselaar EJM, Tank AMGK, Buishand TA (2012) Trends in European precipitation extremes over 1951-2010. International Journal of Climatology, pp n/a-n/a https://doi.org/10.1002/joc. 3619

Vautard R, Yiou P, Otto F, Stott P, Christidis N, van Oldenborgh GJ, Schaller N (2016) Attribution of human-induced dynamical and thermodynamical contributions in extreme weather events. Environmental Research Letters 11(11):114,009. https://doi.org/10. 1088/1748-9326/11/11/114009

Werner P, Gerstengarbe FW, Wechsung F (2008) Grosswetterlagenwetterlagen and precipitation trends in the Elbe River catchment. Meteorol Z 17(1):061-066. https://doi.org/10.1127/0941-2948/ 2008/0263

WMO (2017) Annual bulletin on the climate in wmo region vi - Europe and Middle East - 2017. World Meteorological Organization

WMO (2019) The global climate in 2015-2019. World Meteorological Organization

Wolf G, Brayshaw DJ, Klingaman NP, Czaja A (2018) Quasistationary waves and their impact on European weather and extreme events. Q J R Meteorol Soc 144(717):2431-2448. https:// doi.org/10.1002/qj.3310

Woollings T, Barriopedro D, Methven J, Son SW, Martius O, Harvey B, Sillmann J, Lupo AR, Seneviratne S (2018) Blocking and its response to climate change. Current Climate Change Reports 4(3):287-300. https://doi.org/10.1007/s40641-018-0108-Z

Yarnal B (1993) Synoptic climatology in environmental analysis. Belhaven Press

Publisher's note Springer Nature remains neutral with regard to jurisdictional claims in published maps and institutional affiliations. 